\title{
Facial flatness indices: application in orthodontics
}

\author{
Chimène Y Chalala ${ }^{\text {Corresp., }}{ }^{1}$, Maria E Saadeh ${ }^{1}$, Fouad H Ayoub ${ }^{2}$ \\ ${ }^{1}$ Department of Orthodontics and Dentofacial Orthopedics, Lebanese University and American University of Beirut, Beirut, Lebanon \\ 2 Department of Forensic Odontology, Anthropology and Human Identification, Lebanese University, Beirut, Lebanon \\ Corresponding Author: Chimène Y Chalala \\ Email address: chimenechelela@ul.edu.lb
}

Facial flatness indices have been used in anthropology to discern differences among populations. They were evaluated on skulls from around the world. Aims. 1- to evaluate the use of facial flatness indices in orthodontics and 2- to assess their variation among malocclusions, age and sex. Materials and Methods. 322 cone beam computed tomography radiographs were digitized and three facial indices (frontal, simotic and zygomaxillary) along with three transverse distances (fmo1 - fmo2, zma1- zma2 and n1n2) were assessed and compared between different groups. Results. The zygomaxillary index was increased in Class II (32.6 $\left.\pm 0.42 ; p^{<} 0.001\right)$ and decreased in Class III malocclusions ( $29.4 \pm 0.66 ; p<0.001$ ) compared to Class I (31.18 $\left.\pm 0.3 ; p^{<} 0.001\right)$. The frontal and nasal flatness are not characteristic features of any of the sagittal malocclusions. Facial flatness indices did not differ between males and females and between growing and non-growing patients. Conclusion. The position of subspinale point (A point) forward or backward relative to the zygomaxillary width is a factor of assessment of facial flatness. The zygomaxillary index could be helpful in weighting proportionally the width of the maxilla (expansion) relative to its sagittal position in Class II and Class III malocclusions. 
1 Facial Flatness Indices: Application in Orthodontics

2

3 Chimène Y Chalala ${ }^{1}$, Maria E Saadeh ${ }^{2}$, Fouad H Ayoub ${ }^{3}$

4

$5 \quad{ }^{1}$ Department of Orthodontics and Dentofacial Orthopedics, Lebanese University and American

6 University of Beirut, Beirut, Lebanon.

$7 \quad 2$ Department of Orthodontics and Dentofacial Orthopedics, Lebanese University and American

8 University of Beirut, Beirut, Lebanon.

$9 \quad{ }^{3}$ Department of Forensic Odontology, Anthropology and Human Identification, Lebanese

10 University, Beirut, Lebanon

11

12

13 Chimène Chalala ${ }^{1}$

Corresponding Author:

Riad El-Solh, Beirut 1107 2020, P.O. Box 11-0236, Beirut, Lebanon.Email address: chimenechelela@ul.edu.lb 


\section{Abstract}

44

45

46

47

48

49

50

51

52

53

54

55

56

57

58

59

60

61

62

63

64

65

66

67

68

69

70

71

72

73

74

75

76

77

78

79

80

81

Facial flatness indices have been used in anthropology to discern differences among populations. They were evaluated on skulls from around the world.

Aims. 1- to evaluate the use of facial flatness indices in orthodontics and 2- to assess their variation among malocclusions, age and sex.

Materials and Methods. 322 cone beam computed tomography radiographs were digitized and three facial indices (frontal, simotic and zygomaxillary) along with three transverse distances (fmo1 - fmo2, zma1- zma2 and n1-n2) were assessed and compared between different groups.

Results. The zygomaxillary index was increased in Class II $(32.6 \pm 0.42 ; \mathrm{p}<0.001)$ and decreased in Class III malocclusions $(29.4 \pm 0.66 ; p<0.001)$ compared to Class I $(31.18 \pm 0.3 ; p<0.001)$. The frontal and nasal flatness are not characteristic features of any of the sagittal malocclusions. Facial flatness indices did not differ between males and females and between growing and nongrowing patients.

Conclusion. The position of subspinale point (A point) forward or backward relative to the zygomaxillary width is a factor of assessment of facial flatness.

The zygomaxillary index could be helpful in weighting proportionally the width of the maxilla (expansion) relative to its sagittal position in Class II and Class III malocclusions.

\section{Introduction}

Facial flatness has often been considered in the assessment and evaluation of disparity among populations ${ }^{1-12}$.

Various measurements have been used to evaluate frontal and facial flatnesses in different populations to compare modern to ancient human beings ${ }^{13}$. In 1934, Woo and Morant ${ }^{14}$ evaluated facial flatness on dry skulls and subsequently, many anthropologists have used their method with minor modifications. In 1973, Yamaguchi ${ }^{4}$ proposed three sets of facial flatness measurements: the frontal index, the simotic index (described by Woo and Morant in 1934) ${ }^{14}$ and the zygomaxillary index (described by Alekseev and Debets in 1964) ${ }^{15}$. These indices have been mostly used in anthropological studies where all measurements have been performed on - dry skulls and fossils in many regions around the world ${ }^{13,16-19}$, and none on three-dimensional radiographs.

In orthodontics, facial flatness is usually assessed clinically through the visualization of the face and has been mostly related to maxillary hypoplasia ${ }^{20}$. With the advent of cephalometrics, the position of the maxilla has served as the only practical measurement for flatness through the relative position of point A (subspinale) to the cranial base (SNA angle) ${ }^{21-27}$. Therefore, the application of facial flatness indices on three-dimensional craniofacial radiographs would help describe and assess the flatness at different level of the face (frontal, nasal, zygomatic) and would allow a new perception of facial flatness in the orthodontic field. 
82 The purpose of this study was to evaluate the use of facial flatness indices in orthodontics and 83 assess the association between facial flatness indices and age, sex and sagittal malocclusions,

84 measured through three-dimensional radiographic technology.

85

86

87

88

89 90

91

92

93

94

95

96

97

98

99

100

101

102

103

104

105

106

107

108

109

110

111

112

113

114

115

116

117

118

119

120

121

\section{Materials \& Methods}

Prior to data collection, the study was approved by the Institutional Review Board of the American University of Beirut (IRB ID: BIO-2018- 0065) that waived the need for consent form.

Study population

The pre-treatment cone beam computerized tomography (CBCT) radiographs of 322 patients (121 females, 201 males; age $16.5 \pm 11$ years) were selected from the database of initial orthodontic records in a private radiologic center.

Excluded were subjects who had previous or current orthodontic treatment, craniofacial anomalies, or low-quality pre-treatment CBCT.

Females younger than 16 years old and males younger than 18 years were considered as "growing" ( $\mathrm{n}=244)$, and the remaining as non-growing $(\mathrm{n}=78)$.

The sagittal skeletal malocclusion was classified into 3 groups (Table 1):

Class I $(n=161): 0 \leq A N B \leq 4$;

Class II $(n=136):$ ANB $>4$;

Class III $(n=25):$ ANB $<0$.

\section{Radiographic analysis}

All CBCTs were digitized by one operator (CC) using the View Box 4 imaging software (dHAL Software, Kifissia, Greece).

Nine points were localized on CBCTs as illustrated in Figure 1:

1- Frontomalare orbitale right (fmo1) and left (fmo2): defined as the junction of the frontozygomatic suture and the orbit rim $^{28}$.

2- Nasion (n): defined as the suture between the frontal and nasal bones ${ }^{22}$.

3- Deepest point on the lateral wall of nasal bone right (n1) and left (n2) ${ }^{14}$

4- Nearest point of the median ridge of the nasal bone (n') ${ }^{14}$

5- Zygomaxillary anterius right (zma1) and left (zma2): defined as the most inferior point on the zygomaxillary suture ${ }^{28}$.

6- Subspinale (ss) or point A: defined as the deepest midline point on the premaxilla between the anterior nasal spine and prosthion ${ }^{22}$. 
122 After digitization, three facial indices (frontal, simotic and zygomaxillary) were computed as 123 follows (Fig. 2):

124 - Frontal index of flatness: defined as the percentage of the nasion subtense to the chord between 125 the frontomalaria orbitalia (Fig1, A).

126 - Simotic index: defined as the percentage of the minimum subtense of the median ridge of the 127 nasalia to the simotic chord (minimum horizontal breadth of the nasalia) (Fig1, B).

128 - Zygomaxillary index of flatness: defined as the percentage of subspinale subtense to the chord 129 between the zygomaxillaria anteriora (Fig1, C).

130 The subtenses are obtained by direct measurements of the distance from the summit to the chord.

131 The smaller the value of these indices, the greater the flatness.

132

133

134

135

136

137

138

139

140

141

142

143

144

145

146

147

148

149

150

151

152

153

154

155

156

157

158

159

160

161

162

163

In addition, three transversal measurements were performed to assess the facial width at different levels of the face:

1- fmo1 - fmo2: distance between right and left frontomalaria orbitalia, measured to assess the width of the head;

2- zma1- zma2: distance between right and left zygomaxillaria anteriora, measured to assess the midfacial width;

3- n1-n2: distance representing minimum horizontal breadth of the nasalia, measured to assess the nasal width.

\section{Statistical analysis}

All measurements were normally distributed for all the compared groups as assessed by the Shapiro Wilks normality test. A three-way between subjects analysis of variance (ANOVA) was used to assess the presence of interaction between sex (male, female), growth (growing, adult) and malocclusion (Class I, II, III) on the facial flatness indices and to compare the different groups. When no interaction between the independent variables was detected, a main effect of each variable was reported, followed by multiple comparison post-hoc Tuckey tests when comparing the malocclusion groups in case a statistically significant difference was found. The three-way ANOVA was followed by the "simple effects" for the variables that showed a significant interaction between the independent variable.

The three transversal measurements were compared using a two-way ANOVA to check the effect of sex and growth together.

The Pearson product moment correlation coefficient was performed to correlate the widths of the facial structures at different level of the face.

SPSS statistical package was used to perform all tests, at a level of significance of $\mathrm{p} \leq 0.05$. Inter-rater reliability was calculated on all variables of randomly chosen CBCTs $(n=30)$. Intraclass correlation coefficients ranged between 0.82 and 0.99 . The lowest coefficient 0.82 was obtained for the distance $\mathrm{n} 1-\mathrm{n} 2$, possibly because of the geometric definition of these nasal landmarks (n1 and $\mathrm{n} 2)$ in a 3D record. 


\section{Results}

165

166

167

168

169

170

171

172

173

174

175

176

177

178

179

180

181

182

183

184

185

186

187

188

189

190

191

192

193

194

195

196

197

198

199

200

201

202

203

\section{Reliability of the measurements}

For all three indices, there was no significant three-way or two-way interaction between any of the variables in their effect on the measurements, thus, the main effects of sex, growth and malocclusion were reported and compared, with the estimated marginal means and their standard errors (Table 2).

There was a significant two-way interaction between sex and growth, on the two distances fmo1fmo2 $(\mathrm{F}=8.428, \mathrm{p}=0.004)$ and zma1-zma2 $(\mathrm{F}=4.03, \mathrm{p}=0.046)$, therefore, the simple main effects of each variable, sex and growth, were reported. For the n1-n2 distance, the interaction was not statistically significant, and subsequently, the main effect was reported (Table 3).

\section{Sexual dimorphism}

None of the three indices displayed a statistically significant difference between males and females, regardless of malocclusion and growth ( $p>0.05$, Table 4$)$.

In both growing and adults subgroups, the fmo1-fmo2 distance was statistically significantly larger in males $(93.331 \pm 4.582 \mathrm{~mm}$ and $100.594 \pm 3.501 \mathrm{~mm}$ respectively) compared to females $(90.762 \pm 3.963 \mathrm{~mm}$ and $94.433 \pm 3.544 \mathrm{~mm}$ respectively $)(\mathrm{p}<0.001$; Table 3$)$. The interaction between the growth and sex factors is evident with a smaller average difference in growing individuals $(2.569 \mathrm{~mm})$ compared to adults $(6.161 \mathrm{~mm})$.

The same trend was found for the zma1-zma2 distance, with a significant difference of $1.803 \pm$ $0.713 \mathrm{~mm}$ between growing males and females $(\mathrm{F}=6.401, \mathrm{p}=0.012)$, and a larger difference of $5.155 \pm 1.51 \mathrm{~mm}$ in adults $(\mathrm{F}=11.656, \mathrm{p}=0.001)$.

The $\mathrm{n} 1-\mathrm{n} 2$ distance displayed no significant differences among sex $(\mathrm{F}=0.649 ; \mathrm{p}=0.421$; Table 4$)$. In the total sample, the largest difference between males and females $(2.475 \pm 0.524 \mathrm{~mm})$ was found for fmo1-fmo2 $(F=22.306 ; p<0.001)$ and a difference of $1.675 \pm 0.673 \mathrm{~mm}$ was observed for zma1-zma2 ( $\mathrm{F}=6.198 ; \mathrm{p}=0.013)$. Both fmo1-fmo2 and zma1-zma2 distances were significantly larger in males ( $94.351 \pm 0.414 \mathrm{~mm}$ and $83.964 \pm 0.513 \mathrm{~mm}$ respectively) compared to females $(91.876 \pm 0.321$ and $82.289 \pm 0.412$ ( $\mathrm{p}<0.001$ for fmo1-fmo 2 and $\mathrm{p}=0.013$ for zma1zma2; Table 4).

The ratio of the zygomatic width relative to the frontal width is approximately $0.57 \%$ more in males compared to females. 
204

205

206

207

208

209

210

211

212

213

214

215

216

217

218

219

220

221

222

223

224

225

226

227

228

229

230

231

232

233

234

235

236

237

238

239

240

241

242

243

\section{Effect of growth}

There was no statistically significant difference in the three flatness indices when assessing the main effect of growth ( $\mathrm{p}>0.05$; Table 5).

Both fmo1-fmo2 and zma1-zma2 distances were significantly larger in adults compared to growing individuals, in both males and females subgroups $(\mathrm{p}<0.001$; Table 3$)$. The difference in both distances was found to be approximately twice in males $(7.263 \mathrm{~mm}$ for fmo1-fmo2 and 7.03 $\mathrm{mm}$ for zma1-zma2) compared to females $(3.671 \mathrm{~mm}$ for fmo1-fmo2 and $3.678 \mathrm{~mm}$ for zma1zma2 ( $<<0.001$; Table 5).

No difference between growing and non-growing individuals was detected for the n1-n2 distance $(\mathrm{F}=0.374, \mathrm{p}=0.541$; Table 5).

Similarly, in the total sample, fmo1-fmo2 and zma1-zma2 distances were significantly larger in adults ( $95.776 \pm 0.498 \mathrm{~mm}$ and $85.974 \pm 0.639 \mathrm{~mm}$ respectively) compared to growing individuals $(81.941 \pm 0.361$ and $(\mathrm{p}<0.001$; Table 5). The difference was approximately the same for the frontal and zygomatic width between growing and adults $(3.919 \pm 0.572 \mathrm{~mm}$ for fmo1-fmo 2 and $4.033 \mathrm{~mm}$ for zma1-zma2 ( $<<0.001$; Table 5).

The ratio of the zygomatic width relative to the frontal width increases with age approximately $0.56 \%$ in adults.

\section{Effect of sagittal malocclusion}

When comparing the flatness indices among the three groups of malocclusion (Class I, II and III), there was no statistically significant difference in the frontal $(F=0.064, p=0.938)$ and simotic $(\mathrm{F}=0.137, \mathrm{p}=0.872)$ indices.

Only the zygomaxillary index displayed a significant difference among malocclusions $(\mathrm{F}=8.958$, $\mathrm{p}<0.001)$ : it was significantly larger in Class II $(32.6 \pm 0.42 \mathrm{~mm})$ than Class I $(31.18 \pm 0.3 \mathrm{~mm})$ followed by Class III (29.4 $\pm 0.66 \mathrm{~mm})$ (Table 6).

\section{Correlations}

Moderate positive correlations were detected between transverse dimensions at the level of the head (fmo1-fmo2) and the midface (zma1-zma2) in the total sample $(\mathrm{r}=0.636, \mathrm{p}<0.001)$, and in the males $(r=0.618, p<0.001)$ and females $(r=0.636, p<0.001)$ subsamples. Low positive correlations were found between $\mathrm{n} 1-\mathrm{n} 2$ and fmo1-fmo 2 in the total sample $(\mathrm{r}=0.246, \mathrm{p}<0.001)$ and in males $(\mathrm{r}=0.18, \mathrm{p}=0.048)$ and females $(\mathrm{r}=0.267, \mathrm{p}<0.001)$ separately. No significant correlation was found between $\mathrm{n} 1-\mathrm{n} 2$ and zma1-zma2 ( $\mathrm{p}>0.05)$ (Table 7). 


\section{Discussion}

245

246 Facial flatness has been evaluated through series of measurements on human cranium throughout

247 the years. Some features related to facial flatness were the subject of interpopulation

248 phylogenetic variations ${ }^{\mathbf{1 4 , 2 9}}$. In 1973, Yamaguchi described three facial indices evaluating

249

250

251

252

253

254

255

256

257

258

259

260

261

262

263

264

265

266

267

268

269

270

271

272

273

274

275

276

277

278

279

280

281

flatness at different levels of the face, which have been used only on dry skulls in anthropological studies.

To our knowledge, this is the first study where the flatness measurements are extrapolated and applied on 3D radiographs (CBCTs), to try to induce new interpretations of flatness related to age and sex in orthodontics.

Expectedly, males, in this study, presented wider faces than females as the distances between right and left frotomalareorbitale, zygomaxillary anterius and deepest points on the lateral wall of nasalia were increased in males compared to females.

The transversal growth of the face was the most found at the level of the front, less at the level of the midface and the least at the level of the nose.

The present findings are in agreement with the results of previous studies that found sexual dimorphism in some characteristic phenotypes within the facial structures ${ }^{30-33}$, with men tending to have larger facial features than women and even a larger facial- width to- height ratio ${ }^{34}$.

Wider faces were also noted in adults compared to growing individuals of our total sample. The computation of the difference in width of the front and the midface for the growing and adults groups separately was found to be approximately the same $(4 \mathrm{~mm})$. Additionally, higher correlations were noted in transversal dimensions at the level of the head and the midface but not at the level of the nose. Both distances increase proportionally with age as the ratio of the zygomaxillaryanterius distance over frotomalareorbitale distance remains approximately the same, the difference being only $0.5 \%$. The same trend was found by Hellman ${ }^{35}$ who concluded that the transformation of the infant face into that of the adult occurs by increases in size and some changes in proportions.

On the other hand, facial flatness indices did not differ between males and females and between growing and adults. This might be due to the fact that all individuals of the study sample were ascended from the same ancestry $4,5,7,9,12,14$.

The zygomaxillary index was the only facial flatness index that significantly differed among malocclusion classes: it was significantly decreased in Class III and increased in Class II compared to Class I. As the frontal and simotic index were not different among malocclusions, it could be concluded that the frontal and nasal flatness are not characteristic features of any of the sagittal malocclusions classes.

Peer) reviewing PDF | (2018:12:33229:1:2:NEW 20 Mar 2019) 
282 Therefore, assessment of flatness would be limited to the anterior protrusion of subspinale point 283 with the sole difference that it is weighed relative to the breadth of the zygomatic region and not 284 to the cranial base.

285 Class II malocclusion have been evaluated through the literature by the amount of maxillary 286 protrusion (subspinale region) relative to the profile (Nasion) ${ }^{21-23}$. Controversies were found 287 regarding the association between transverse dentoskeletal deficiency of the maxilla and its 288 protrusion in Class II malocclusion. In 2005, Franchi and Baccetti ${ }^{36}$ had found this association to 289 be highly present in Class II subjects mainly with mandibular retrusion. On the contrary, 290 Vasquez et al in 2009 had reported no significant transverse deficiency was associated with Class 291 II malocclusion when it is characterized by maxillary skeletal protrusion ${ }^{37}$. Their transversal 292 measurements were expanded to different levels of the face. The outcomes of our study can be 293 helpful to clarify these controversies as the zygomaxillary index was found significantly 294 increased in Class II subjects indicating maxillary protrusion and/or transverse deficient maxilla. 295 Consequently, it will be important to evaluate the zygomaxillary index changes between Class II 296 division 1 and Class II division 2 as the morphologic features are different between the two 297 groups. Specifically, the differential between skeletal projection and dentoalveolar projection in 298 the face might be better understood through the evaluated indices. As orthodontists, we mainly 299 affect the dentoalveolar component. Moreover, it will be valuable to compare this index between 300 Class II malocclusions associated with mandibular retrognathism and those due to maxillary 301 protrusion. In either case, maxillary expansion, if needed, would normalize the zygomaxillary 302 index in Class II subjects and permit to achieve more harmonious and proportional facial 303 features.

304

305

306

307

308

309

310

311

312

313

314

315

316

317

318

319

320
In the Class III group, the zygomaxillary index was significantly decreased reflecting more midfacial flatness. According to our study, this flatness at the midface is not noticeable between growing and adults as no significant difference was perceived regarding this index between both groups. Therefore, the flatness of the midface proportionally to the midfacial width would not be worsened with age regardless of mandibular prognathism.

Many systematic reviews and meta-analyses have analyzed the protraction of maxilla using the face mask appliance. They showed a clinically significant improvement in the sagittal relationship between the jaws and forward movement of subspinale point ${ }^{\mathbf{3 8 - 4 1}}$. Subsequently, it might be valuable to calculate the zygomaxillary index after maxillary protraction in Class III growing patients to check if any changes in width would have occurred at the level of the zygomaxillary area specially that histological changes of the circumaxillary sutures have been shown in several animal studies ${ }^{42-45}$. In other words, the calculation of the zygomaxillary index before and after maxillary protraction with a face mask would determine if the correction of the Class III malocclusion was achieved by a skeletal or a dental effect and if the midfacial flatness was corrected.

Peer) reviewing PDF | (2018:12:33229:1:2:NEW 20 Mar 2019) 
321 Despite the substantial size of our sample, further research shall help validate our findings, by

322

323

324

325

326

327

328

329

330

331

332

333

334

335

336

337

338

339

340

341

342

343

344

345

346

347

348

349

350

351

352

353

354

355

356

357

358

359

360

361

362

363

increasing the sample size within each group. A longitudinal study would better answer the effect of growth on the measured indices, although it is hard to achieve, given the irradiation risk inherent to CBCTs. Future studies would also help investigate more thoroughly the difference in these indices before and after orthopedic Class III correction.

While the zygomaxillary index provides mainly diagnostic instructions, it may indicate treatment limitations. Additional research would hopefully determine such associations following treatment of patients with various indices.

\section{Conclusions}

1- Facial flatness indices evaluation is important in orthodontics to appraise the harmonization within the different proportions of the face.

2- The zygomaxillary index is decreased in Class III and increased in Class II malocclusions.

3- In Class II malocclusion the calculation of the zygomaxillary index may be helpful in clarifying the controversies regarding the association between transverse maxillary deficiency and maxillary protrusion.

4- Facial flatness assessment is evaluated according to the position of subspinale point and its projection forward or backward relative to the zygomaxillary width so proportionally to the width of the midface.

\section{References}

1- Debets GF. Anthropological studies in the Kamchatka region. Trudi Instituta Etnografii. $1951 ; 17: 1-263$.

2- Oschinsky L. Facial flatness and cheekbone morphology in Arctic Mongoloids. Anthropol NS. 1962; 4349- 377.

3- Alekseev VP. Anthropology of Siberian peoples. In: Laughlin WW, Harper AB, editors. The first Americans: origins, affinities, and adaptations. Stuttgart: Gustav Fischer. 1979; 57-90.

4- Yamaguchi B. Facial flatness measurements of the Ainu and Japanese crania. Bull Natl Sci Mus. 1973; 16:161-171.

5- Yamaguchi B. A study on the facial flatness of the Jomon crania. Bull Natl Sci Mus Tokyo. 1980; 6:21-28.

6- Bulbeck D. 1981. Continuities in Southeast Asian evolution since the late Pleistocene: some new material described and some old questions reviewed. MA thesis, Australian National University. Canberra, Australia.

Peer) reviewing PDF | (2018:12:33229:1:2:NEW 20 Mar 2019) 
364 365

366

367

368

369

370

371

372

373

374

375

376

377

378

379

380

381

382

383

384

385

386

387

388

389

390

391

392

393

394

395

396

397

398

399

400

401

402

403

404

405

406

7- Rak Y. The Neanderthal face: a new look at an old face. J Hum Evol. 1986; 15:151-164.

8- Trinkaus E. The Neandertal face: evolutionaryand functional perspectives on a recent hominid face. J Hum Evol. 1987; 16:429-443.

9- Gill GW, Hughes SS, Bennett SM, Gilbert BM. Racial identification from the midfacial skeleton with special reference to American Indians and whites. J Forensic Sc. 1988; 33:9299.

10- Pope GG. Evolution of the zygomaticomaxillary region in the genus Homo and its relevance to the origin of modern humans. J Hum Evol. 1991; 21:189-213.

11- Pope GG. Craniofacial evidence for the origin of modern humans in China. Yrbk Phys Anthropol. 1992; 35: 243-298.

12- Ishida H. Flatness of facial skeletons in Siberian and other circum-Pacific populations. Z Morphol Anthropol. 1992; 79:53-67.

13- Hanihara T. Frontal and Facial Flatness of Major Human Populations. Am J Phys Anthropol. 2000; 111:105-134.

14- Woo TL, Morant G M. A biometric study of the "flatness" of the facial skeleton in man. Biometrika. 1934; 26: 196-250.

15- Alekseev VP, Debets GF. Kraniometria. Metodika anthropologitsheskh isledovaniy. Izd. Nauka, Moskva. 1964; 128.

16- Fukase H, Wakebe T, Tsurumoto T, Saiki K, Fujita M, Ishida H. Facial characteristics of the prehistoric and early-modern inhabitants of the Okinawa islands in comparison to the contemporary people of Honshu. Anthropol Sci., 2012a; 120: 23-32.

17- Ishida H, Dodo Y. Cranial Variation in Prehistoric Human Skeletal Remains from the Marianas. American Journal of Physical Anthropology.1997; 104: 399-410.

18- Green H. 2007. Cranial variation of contemporary East Asians in a global context. Ph.D. Thesis, University of New South Wales.

19- Dodo Y. A Human Skull of the Epi-Jomon Period from the Minami-Usu Six Site, Date, Hokkaido. J. Anthrop. Soc. Nippon. 1983; 91 (2): 169-186.

20- Naini, FB, Gill DS. Facial Aesthetics: 2. Clinical Assessment. Dent Update.2008; 35: 159170 . 
407 408 409

410

411

412

413 414

415

416

417

418

419

420

421

422

423

424

425

426

427

428

429 430

431

432

433

434

435

436

437

438

439

440

441

442

443

444

445

446

447 448

21- Steiner C. Cephalometrics for you and me. American Journal of Orthodontics. 1953; 39:72955.

22- Downs WB. Variations in Facial Relationship: Their Significance in Treatment and Prognosis. The Angle Orthodontist. 1949; 19 (3):145-155.

23- McNamara JA. A method of cephalometric evaluation. Ann Arbor. 1984; 86(6): 449-69.

24- Jarabak JR, Fizzel JA. (1972) Technique and treatment with light wire edgewise appliances. (2nd. ed.), St. Louis: Mosby.

25- Ricketts RM. A foundation for cephalometric communication. American Journal of Orthodontics. 1960; 46:330-57.

26- Ricketts RM. Cephalometric analysis and synthesis. The Angle Orthodontist. 1961; 31(3):141-56.

27- Rickets RM. Perspectives in clinical application of cephalometrics. The Angle Orthodontist. $1981 ; 51: 115-50$.

28- Martin R and Saller K. Lehrbuch der anthropologie. Fischer Stuttgart, 1957.

29- Weidenreich F. Skull of Sinanthropus pekinensis. Palaeontologia Sinica 1943; N. S. D 10.

30- Barber N. The evolutionary psychology of physical attractiveness: sexual selection and human morphology. Ethology and Sociobiology. 1995; 16: 395-424.

31- Penton-Voak IS, Jones BC, Little AC, Baker S, Tiddeman B. Burt DM, Perrett DI. Symmetry, sexual dimorphism in facial proportions and male facial attractiveness. Proceedings of the Royal Society B-Biological Sciences. 2001; 268: 1617-1623.

32- Perrett D I, Lee K J, Penton-Voak I, Rowland D, Yoshikawa S, Burt, D M, Henzl S P, Castles D L, Akamatsu S. Effects of sexual dimorphism on facial attractiveness. Nature. 1998; 394: 884-887.

33- Enlow D. Handbook of Facial Growth. 1982; Philadelphia: Saunders.

34- Weston EM, Friday AE, Lio P. Biometric Evidence that Sexual Selection Has Shaped the Hominin Face. 2007; PLoS ONE, 2, e710.

35- Hellman M. The face in its developmental career. Dental Cosmos. 1935; 75: 685-689. 
449

450

451

452

453

454

455

456

457

458

459

460

461

462

463

464

465

466

467

468

469

470

471

472

473

474

475

476

477

478

479

480

481

482

483

484
36- Franchi L, Baccetti T. Transverse maxillary deficiency in Class II and Class III malocclusions: a cephalometric and morphometric study on postero-anterior films. Orthod Craniofac Res 2005;8: 21-8

37- Vasquez MJ, Baccetti T, Franchi L, McNamara JA Jr. Dentofacial features of Class II malocclusion associated with maxillary skeletal protrusion: A longitudinal study at the circumpubertal growth period. Am J Orthod Dentofacial Orthop 2009; 135: 568.e1-568.e7.

38- Zhang W, Hong-Chen Q, Yu M, Zhang Y. The effects of maxillary protraction with or without rapid maxillary expansion and age factors in treating class III malocclusion: a meta analysis. PLoS One. 2015 June.

39- Kim JH, Viana MA, Graber TM, Omerza FF, BeGole EA. The effectiveness of protraction facemask therapy: a meta-analysis. Am J Orthod Dentofacial Orthop.1999; 115: 675-685.

40- Jager A, Braumann B, Kim C, Wahner S. Skeletal and dental effects of maxillary protraction in patients with angle class III malocclusion: A meta-analysis. J Orofac Orthop. 2001;62:275-284.

41- Toffol LD, Pavoni C, Baccetti T, Franchi L, Cozza P. Orthopedic treatment outcomes in Class III malocclusion. A systematic review. Angle Orthod. 2008;78:561-573.

42- Dellinger EL A preliminary study of anterior maxillary displacement. Am J Orthod. 1973; 63:509-516.

43- Jackson GW, Kokich VG, Shapiro PA. Experimental and postexperimentalresponse to anteriorly directed extraoral force in young Macaca nemestrina. Am J Orthod. 1979;75:318333.

44- Kambara T. Dentofacial changes produced by extraoral force in Macaca irus. Am J Orthod. 1977;71:249-277.

45- Nanda R. Protraction of maxilla in rhesus monkeys by controlled extraoral forces. Am J Orthod 1978;74:121-141.

46- Angle, E.H. Classification of malocclusion. Dental Cosmos. 1899; 41: 248-264. 


\section{Figure 1}

Digitized points from a frontal view

fmo1: Right Frontomalare orbitale; fmo2: Left Frontomalare orbitale; $n$ : Nasion; $n$ ': Nearest point of the median ridge of the nasal bone; $n 1$ : Right deepest point on the lateral wall of nasal bone; $n 2$ : Left deepest point on the lateral wall of the nasal bone ; zma1: Right zygomaxillary anterius; zma2: Left zygomaxillary anterius.

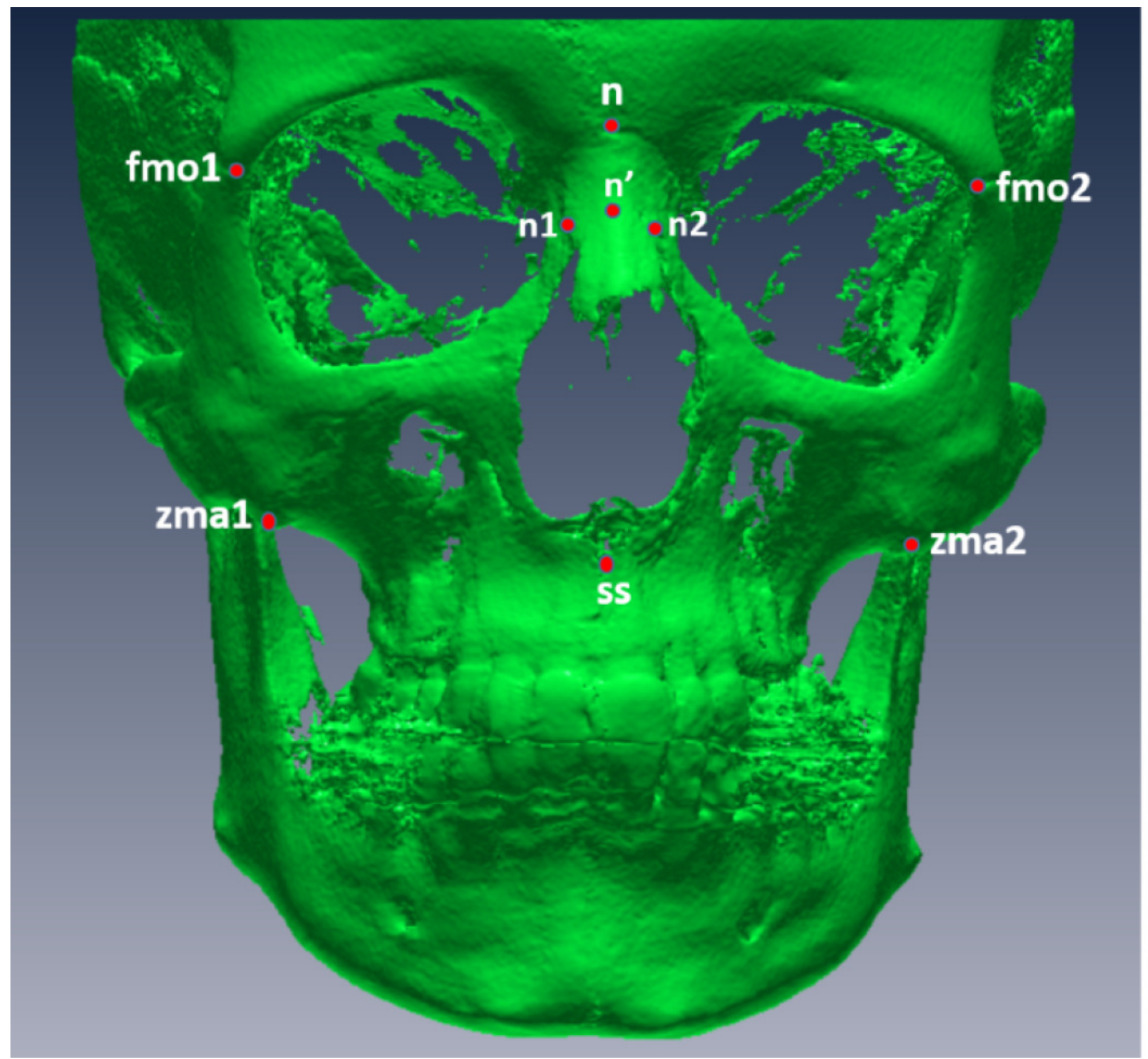




\section{Figure 2 (on next page)}

Figure 2

Figure 2: 1. Frontal chord; 2. Frontal subtense; 3. Simotic chord; 4. Simotic subtense; 5. Zygomaxillary chord; 6. Zygomaxillary subtense. A: Frontal index: denominator: the frontal chord between the frontomalaria orbitalia, numerator: the subtense of the nasion from the frontal chord. B: Simotic index: denominator: the simotic chord (the minimum horizontal breadth of the nasal bone, numerator: simotic subtense (the minimum distance from the midian ridge of the nasal bone to the simotic chord. C: Zygomaxillary index: denominator: the zygomaxillary chord between the zygomaxillaria anteriora, numerator: zygomaxillary subtense (distance from the subspinale to the zygomaxillary chord). 


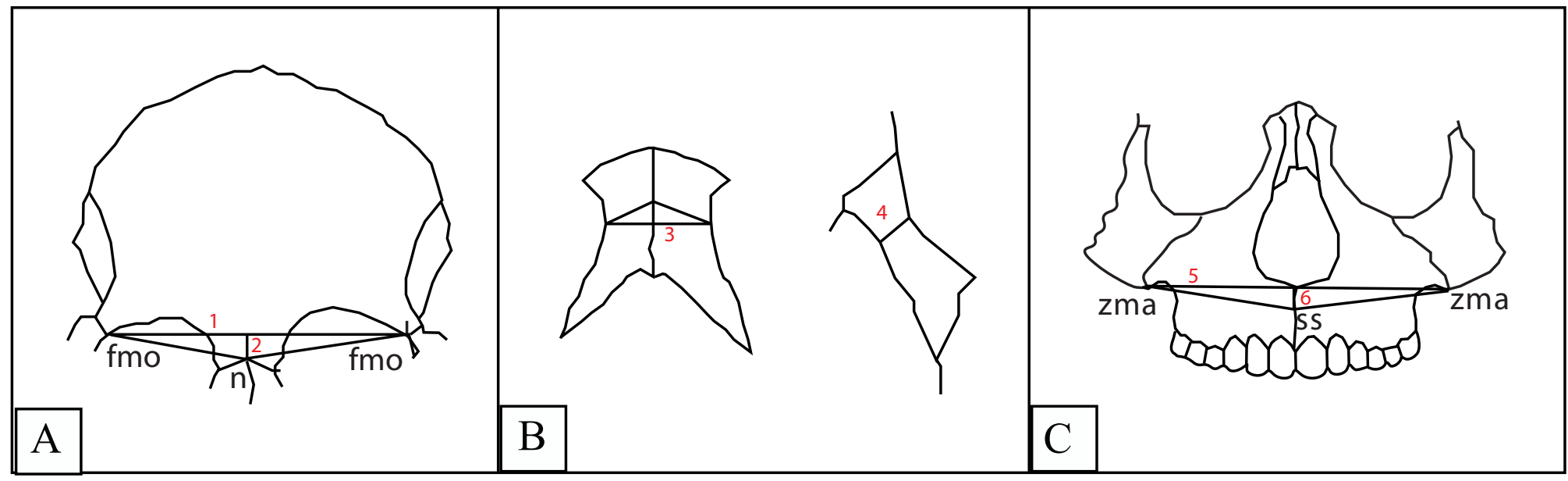




\section{Table $\mathbf{1}$ (on next page)}

all tables are illustrated in one DOC file 
3 Table 1: Definitions of the acronyms and specific terms

4

Acronym Definition

ANB Cephalometric angular measurement formed by the line connecting A point (subspinale) to nasion and another joining nasion to B point (supramentale). This angle describes the anteroposterior relationship between the mandible and the maxilla.

Class I Dental relationship described by Angle ${ }^{46}$ in which the mesiobuccal cusp of the upper first molar is aligned with the buccal groove of the mandibular first molar.

Class II The mesiobuccal cusp of the upper first molar is anterior to the mesiobuccal groove of the lower first molar.

Class III The mesiobuccal cusp of the maxillary first molar lies posteriorly to the mesiobuccal groove of the mandibular first molar.

5

6 


\section{Table 2 (on next page)}

Three-way ANOVA for facial indices with sex, growth and sagittal malocclusion as factors 
1

2

3

4

5

6

7

8

9

10

11

12

13

14

15

16

17

18

19

20

21

22

23

24

25

26

27

28

Table 2: Three-way ANOVA for facial indices with sex, growth and sagittal malocclusion as factors

\begin{tabular}{|c|c|c|c|c|c|c|c|}
\hline \multirow[b]{2}{*}{ Variable } & \multirow[b]{2}{*}{$\mathrm{df}$} & \multicolumn{2}{|c|}{$\begin{array}{l}\text { Frontal } \\
\text { index }\end{array}$} & \multicolumn{2}{|c|}{$\begin{array}{c}\text { Simotic } \\
\text { index }\end{array}$} & \multicolumn{2}{|c|}{$\begin{array}{c}\text { Zygomaxillary } \\
\text { index }\end{array}$} \\
\hline & & $\mathrm{F}$ & $\mathrm{p}$ & $\mathrm{F}$ & $\mathrm{p}$ & $\mathrm{F}$ & $\mathrm{p}$ \\
\hline Sex & 1 & 0.183 & 0.669 & 1.255 & 0.264 & 0.219 & 0.64 \\
\hline Growth & 1 & 2.17 & 0.142 & 3.462 & 0.064 & 2.641 & 0.105 \\
\hline Malocclusion & 2 & 0.064 & 0.938 & 0.137 & 0.872 & 8.958 & $<0.001$ ** \\
\hline Sex *Growth & 1 & 0.292 & 0.589 & 0.352 & 0.553 & 0.065 & 0.798 \\
\hline Sex *Malocclusion & 2 & 0.422 & 0.656 & 0.264 & 0.768 & 0.022 & 0.978 \\
\hline Growth*Malocclusion & 2 & 0.857 & 0.425 & 1.188 & 0.306 & 1.014 & 0.364 \\
\hline Sex*Growth*Malocclusion & 2 & 0.538 & 0.585 & 0.345 & 0.709 & 0.863 & 0.423 \\
\hline
\end{tabular}




\section{Table 3(on next page)}

Two-way ANOVA results for the transverse measurements with growth and sex as factors 
1

2

3

4

5

\begin{tabular}{|c|c|c|c|c|c|c|c|}
\hline \multirow[b]{2}{*}{ Variable } & \multirow[b]{2}{*}{$\mathrm{df}$} & \multicolumn{2}{|c|}{ fmo1-fmo2 } & \multicolumn{2}{|c|}{ zma1-zma2 } & \multicolumn{2}{|c|}{ n1-n2 } \\
\hline & & $\mathrm{F}$ & $\mathrm{p}$ & $\mathrm{F}$ & $\mathrm{p}$ & $\mathrm{F}$ & $\mathrm{p}$ \\
\hline Sex & 1 & 49.76 & $<0.001^{* *}$ & 17.367 & $<0.001^{* *}$ & 0.649 & 0.421 \\
\hline $\mathrm{Gr}$ & 1 & 78.065 & $<0.001^{* *}$ & 41.129 & $<0.001^{* *}$ & 0.374 & 0.541 \\
\hline Sex *Growth & 1 & 8.428 & $0.004^{* *}$ & 4.03 & $0.046^{*}$ & 0.063 & 0.801 \\
\hline
\end{tabular}

6 *Statistically significant, $\mathrm{p}<0.05 ; * *$ statistically significant. $\mathrm{p}<0.01$. growth and sex as factors
Table 3: Two-way ANOVA results for the transverse measurements with

8

9

10

11

12 


\section{Table 4 (on next page)}

Difference in facial indices and transverse measurements between males and females 
Table 4: Difference in facial indices and transverse measurements between males and females

7

\begin{tabular}{cccc}
\hline Males & Females & Difference (M-F) & Univariate \\
$(\mathrm{n}=\mathbf{1 2 1})$ & $(\mathrm{n}=\mathbf{2 0 1})$ & ANOVA
\end{tabular}

\begin{tabular}{lcccccccc} 
& EMM & SE & EMM & SE & Mean & SE & F & p \\
\hline Frontal index & 18.23 & 0.41 & 18.01 & 0.31 & 0.22 & 0.51 & 0.183 & 0.669 \\
Simotic index & 62.45 & 1.85 & 59.85 & 1.41 & -2.6 & 2.33 & 1.255 & 0.264 \\
$\begin{array}{l}\text { Zygomaxillary } \\
\text { index }\end{array}$ & 31.19 & 0.45 & 30.93 & 0.34 & 0.26 & 0.56 & 0.219 & 0.64 \\
fmo1-fmo2 & $\mathbf{9 4 . 3 5 1}$ & $\mathbf{0 . 4 1 4}$ & $\mathbf{9 1 . 8 7 6}$ & $\mathbf{0 . 3 2 1}$ & $\mathbf{2 . 4 7 5}$ & $\mathbf{0 . 5 2 4}$ & $\mathbf{2 2 . 3 0 6}$ & $<\mathbf{0 . 0 0 1}{ }^{* *}$ \\
\multicolumn{1}{c}{ Growing } & 93.331 & 4.582 & 90.762 & 3.963 & 2.569 & 0.528 & 23.645 & $<0.001^{* *}$ \\
Non growing & 100.594 & 3.501 & 94.433 & 3.544 & 6.161 & 0.119 & 30.311 & $<0.001^{* *}$ \\
zma1-zma2 & $\mathbf{8 3 . 9 6 4}$ & $\mathbf{0 . 5 1 3}$ & $\mathbf{8 2 . 2 8 9}$ & $\mathbf{0 . 4 1 2}$ & $\mathbf{1 . 6 7 5}$ & $\mathbf{0 . 6 7 3}$ & $\mathbf{6 . 1 9 8}$ & $\mathbf{0 . 0 1 3}$ \\
\multicolumn{1}{c}{ Growing } & 82.976 & 6.44 & 81.173 & 5.073 & 1.803 & 0.713 & 6.401 & $0.012^{*}$ \\
Non growing & 90.006 & 3.648 & 84.851 & 5.125 & 5.155 & 1.51 & 11.656 & $0.001^{* *}$ \\
n1-n2 & $\mathbf{1 0 . 5 1 9}$ & $\mathbf{0 . 2 5 6}$ & $\mathbf{1 0 . 2 7 9}$ & $\mathbf{0 . 1 5}$ & $\mathbf{0 . 2 3 9}$ & $\mathbf{0 . 2 9 7}$ & $\mathbf{0 . 6 4 9}$ & $\mathbf{0 . 4 2 1}$ \\
\hline 8
\end{tabular}

8 EMM: Estimated Marginal Means; SE: Standard Error

9 *Statistically significant, $\mathrm{p}<0.05 ; * *$ Statistically significant. $\mathrm{p}<0.01$.

10

11

12

13

14

15 


\section{Table 5 (on next page)}

Difference in facial indices and transverse measurements between growing vs nongrowing patients 
1
2
3
4

Table 5: Difference in facial indices and transverse measurements between growing

Table 5: Difference in facial indices and transverse measurements between growing
vs non-growing patients vs non-growing patients

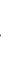

\begin{tabular}{|c|c|c|c|c|c|c|c|c|}
\hline & \multicolumn{2}{|c|}{$\begin{array}{l}\text { Growing } \\
(n=244)\end{array}$} & \multicolumn{2}{|c|}{$\begin{array}{c}\text { Adults } \\
(n=78)\end{array}$} & \multicolumn{2}{|c|}{ Difference (G-A) } & \multicolumn{2}{|c|}{$\begin{array}{c}\text { Univariate } \\
\text { ANOVA }\end{array}$} \\
\hline & ЕММ & SE & EMM & SE & Mean & SE & $F$ & $p$ \\
\hline Frontal index & 18.49 & 0.24 & 17.74 & 0.45 & 0.75 & 0.51 & 2.17 & 0.142 \\
\hline Simotic index & 58.99 & 1.11 & 63.32 & 2.04 & 4.33 & 2.33 & 3.462 & 0.064 \\
\hline $\begin{array}{l}\text { Zygomaxillary } \\
\text { index }\end{array}$ & 31.52 & 0.27 & 30.61 & 0.49 & 0.91 & 0.56 & 2.641 & 0.105 \\
\hline fmo1-fmo2 & 91.857 & 0.282 & 95.776 & 0.498 & -3.919 & 0.572 & 46.896 & $<0.001^{* *}$ \\
\hline Males & 93.331 & 4.582 & 100.594 & 3.501 & -7.263 & 1.067 & 46.296 & $<0.001^{* *}$ \\
\hline Females & 90.762 & 3.963 & 94.433 & 3.544 & -3.671 & 0.626 & 34.381 & $<0.001^{* *}$ \\
\hline zma1-zma2 & 81.941 & 0.361 & 85.974 & 0.639 & -4.033 & 0.734 & 30.201 & $<0.001^{* *}$ \\
\hline Males & 82.976 & 6.44 & 90.006 & 3.648 & -7.03 & 1.44 & 23.823 & $<0.001^{* *}$ \\
\hline Females & 81.173 & 5.073 & 84.851 & 5.125 & -3.678 & 0.845 & 18.962 & $<0.001^{* *}$ \\
\hline$n 1-n 2$ & 10.308 & 0.127 & 10.490 & 0.269 & -0.182 & 0.297 & 0.374 & 0.541 \\
\hline
\end{tabular}

$5 \quad *$ Statistically significant, $\mathrm{p}<0.05 ; * *$ Statistically significant. $\mathrm{p}<0.01$. 6

7

8

9 


\section{Table 6(on next page)}

Difference in facial indices between sagittal malocclusions (Class I, Class II and Class III) 
1

2 Table 6: Difference in facial indices between sagittal malocclusions

3

(Class I, Class II and Class III)

4

Class I Class II Class II

$(n=161)$

$(n=136)$

$(n=25)$

Univariate

EMM

SE

EMM

SE

\begin{tabular}{lcccccccc} 
Frontal index & 18.02 & 0.28 & 18.17 & 0.38 & 18.17 & 0.6 & 0.064 & 0.938 \\
Simotic index & 61.32 & 1.26 & 60.35 & 1.74 & 61.78 & 2.75 & 0.137 & 0.872 \\
$\begin{array}{l}\text { Zygomaxillary } \\
\text { index }\end{array}$ & $31.18^{\mathrm{a}}$ & 0.3 & $32.6^{\mathrm{b}}$ & $0.42^{\mathrm{c}}$ & 29.4 & 0.66 & 8.958 & $\mathbf{< 0 . 0 0 1}^{* *}$ \\
\hline
\end{tabular}

Mean

\begin{tabular}{lcccccccc} 
Frontal index & 18.02 & 0.28 & 18.17 & 0.38 & 18.17 & 0.6 & 0.064 & 0.938 \\
Simotic index & 61.32 & 1.26 & 60.35 & 1.74 & 61.78 & 2.75 & 0.137 & 0.872 \\
$\begin{array}{l}\text { Zygomaxillary } \\
\text { index }\end{array}$ & $31.18^{\mathrm{a}}$ & 0.3 & $32.6^{\mathrm{b}}$ & $0.42^{\mathrm{c}}$ & 29.4 & 0.66 & 8.958 & $\mathbf{< 0 . 0 0 1}^{* *}$ \\
\hline
\end{tabular}

SE

61.78

0.6 ANOVA

$5 \quad *$ Statistically significant, $\mathrm{p}<0.05 ; * *$ Statistically significant. $\mathrm{p}<0.01$; Alphabetic subscripts denote

6 significantly different column means at $\mathrm{p}<0.05$ (Bonferroni correction).

7

8

9 


\section{Table 7 (on next page)}

Correlations between the different transversal distances of the face in the total sample and in the males and females subgroups 
1

2

3

4

5

6

Table 7: Correlations between the different transversal distances of the face in the total sample and in the males and females subgroups

\begin{tabular}{ccccc}
\hline & \multicolumn{2}{c}{ zma1-zma2 } & \multicolumn{2}{c}{ n1-n2 } \\
\hline & $\mathrm{r}$ & $\mathrm{p}$ & $\mathrm{r}$ & $\mathrm{p}$ \\
\hline TOTAL & & & & \\
\hline fmo1-fmo2 & 0.636 & $<0.001^{* *}$ & 0.246 & $<0.001^{* *}$ \\
zma1-zma2 & -- & -- & 0.077 & 0.168 \\
\hline MALES & & & & \\
\hline fmo1-fmo2 & 0.618 & $<0.001^{* *}$ & 0.18 & $0.048^{*}$ \\
zma1-zma2 & -- & -- & 0.011 & 0.907 \\
\hline FEMALES & & & & \\
\hline fmo1-fmo2 & 0.636 & $<0.001^{* *}$ & 0.267 & $<0.001 * *$ \\
zma1-zma2 & -- & -- & 0.106 & 0.134 \\
\hline
\end{tabular}

${ }^{*}$ Statistically significant, $\mathrm{p}<0.05 ;{ }^{*}$ Statistically significant. $\mathrm{p}<0.0 .1$

8

9

10

11

12 